\title{
Knowing the differences in the class effect of pharmacologic agents will improve our individualized medical prescription
}

\author{
Osmar Antonio Centurión ${ }^{1,2 *}$, José Carlos Candia ${ }^{2}$ and José Fernando Alderete ${ }^{2}$ \\ ${ }^{1}$ Department of Health Sciences's Investigation, Sanatorio Metropolitano. Fernando de la Mora, Paraguay \\ ${ }^{2}$ Cardiology Department, First Department of Internal Medicine, Clinic Hospital. Asunción National University, San Lorenzo, Paraguay
}

For more than 3 decades ago there has been an increasing interest and utilization of the phrase "class effect" given to a group of drug agents that somehow share similar pharmacologic and therapeutic effects sharing some pharmacodynamics characteristics. There has been a tendency to express this "class effect" with anti-arrhythmic agents, angiotensin converter enzyme (ACE) inhibitors, beta-blocker agents, anti-dyslipidemic drugs, and the list goes on. Although, there is no accepted definition of the term "class effect" in the literature, it is widely used $[1,2]$. This tendency to call "class effect" happens with practically every group of drug agents when most of the times the only similarity they share is to be in the same class group.

The relatively similar results of some randomized clinical studies on ACE inhibitors done in the 80s lead to the intuitive generalization of their clinical effects facilitating the superfluous assumption that all ACE inhibitors share the "class effect" that makes them identical [3-5]. However, studies performed in the new millennium era have shown the differences between drug agents that belong to the same class group. The pharmacological agents are typically grouped based on one common mechanism of action. The different drugs of a class group are often divided into subclasses based on the chemical structure. It is also interesting to note that all drugs usually have multiple mechanisms of action determined by their unique chemical structure. The scientific knowledge about these drugs have proved variations in the half-life, in the liposoluble properties, the route of metabolism and elimination, serum and tissue levels, the dose-response relation, and the route of administration for a better therapeutic effectiveness. When it is considered the marked differences in the chemical structure among the different drugs of a same group, it is not surprising that they may have different clinical actions and outcomes. Indeed, the pharmacodynamic differences determine the different results obtained on later studies performed with ACE inhibitors [6-8]. Those ACE inhibitors with longer half-life and better tissue penetration had more significant reduction in clinical events. For example, it was surprising to learn about the adverse effects, negative results and increased mortality with intravenous enalapril in patients with myocardial infarction in the CONSENSUS II trial [9]. Specially, after knowing about the beneficial effects of oral enalapril utilized in the CONSENSUS I trial [3]. The adverse events probably occur due to the pro-ischemic effects of the secondary hypotension with the intravenous administration of enalapril. Evidently, if the same drug with a comparable dose utilized for the same disease but with a different route of administration can generate surprisingly different results, how much more different would be the use of two drugs that share the same class group. The scenario turns even more confusing when we learn the results of the SAVE trial showing that an ACE inhibitor significantly reduces ischemic events [10]. Later on, it is demonstrated a variety of their positive effects on the vascular endothelium and mediator substances of inflammation [10-13]. In this context, it is well known that some patients may present torsade des points after the intravenous administration of amiodarone, while they did not have any pro-arrhythmia on long-term oral amiodarone [14-16]. This fact underlines the different results with different routes of administration of the same drug.

Other clinical studies have shown beneficial effects of the ACE inhibitors on sudden cardiac death, and on atrial fibrillation, while others demonstrated a deleterious effect [17-20]. The mechanisms responsible for these diverse actions are produced by the various tissular effects of the drug on the vascular endothelium in individual subjects. Therefore, while the ACE inhibitors can share a hemodynamic effect and a similar clinical outcome in heart failure patients, the tissular effect of the drug varies considerably [13].

Are we prescribing the correct drug to the adequate patient according to medicine based evidence? Sometimes, industrial marketing and several other factors may exert certain pressure on the clinician to utilize a cheaper agent, or to employ a lower dose than the one that was shown to be effective in the clinical trials. It is highly prudent to assume that untested drug agents of a certain class are not interchangeable for a specific indication until there is enough scientific clinical evidence. A drug agent that has not been tested in clinical trials with longterm follow-up lacks the appropriate long-term safety. This is a very important matter since a number of individual pharmacological agents of established drug classes have been found to cause major complications and deleterious effects leading to drug withdrawal after FDA approval and post-marketing of the drug. Large-scale, randomized clinical trials with long-term follow-up can provide the necessary tools to properly evaluate long-term safety and for determining adequate data for riskbenefit ratios. We should be prescribing the specific pharmacological

Correspondence to: Prof. Osmar Antonio Centurión, MD, PhD, FACC, FAHA, Professor of Medicine. Asuncion National University, Department of Health Sciences's Investigation, Sanatorio Metropolitano, Teniente Ettiene 215 c/ Ruta Mariscal Estigarribia, Fernando de la Mora. Paraguay; E-mail: osmarcenturion@ hotmail.com

Key words: Class effect, Medical prescription, Clinical Trial

Received: June 03, 2017; Accepted: July 10, 2017; Published: July 14, 2017 
agent utilized in the randomized clinical trial at the same dose and for the same illness of the specified population in order to obtain similar beneficial results as the clinical study. Two drug agents of the same class group should not be considered to have similar therapeutic effects until this similarity is proved in a head-to-head comparison in large scale, controlled, double blind, and randomized clinical trials with long-term follow-up.

Therefore, all pharmacologic agents of the same class group are not the same, and the medicine based evidence supports in favor of a detailed and meticulous analysis of the concept of "class effect". It is surprising that the discovery of the vast complexity and enormous differences of the pharmacologic agents of the same class group could not eradicate the concept of "class effect" ingrained in physicians. The complete understanding of the explosive scientific, social and medical evolution, besides, the recognition of the proper correction of wrong medical concepts should modify the point of view of the physician about the conception of the "class effect" of drug agents. This is with the sole intention of dissipating and eliminating this vague concept from the minds of physicians.

\section{References}

1. Furberg CD (1999) Natural statins and stroke risk. Circulation 99: 185-188. [Crossref]

2. Furberg CD, Herrington DM, Psaty BM (1999) Are drugs within a class interchangeable? Lancet 354: 1202-1204. [Crossref]

3. CONSENSUS Trial Study Group (1987) Effects of enalapril on mortality in severe congestive heart failure. Results of the Cooperative North Scandinavian Enalapril Survival Study (CONSENSUS). N Engl J Med 316: 1429-1435. [Crossref]

4. [No authors listed] (1995) Guidelines for the evaluation and management of heart failure. Report of the American College of Cardiology/American Heart Association Task Force on Practice Guidelines (Committee on Evaluation and Management of Heart Failure). J Am Coll Cardiol 26: 1376-1398. [Crossref]

5. O'Keefe JH, Wetzel M, Moe RR, Bronsnahan K, Lavie CJ. (2001) Should an angiotensin-converting enzime inhibitor be standard therapy for patients with atherosclerotic disease? J Am Coll Cardiol 37: 1-8. [Crossref]

6. Pitt B (1994) Use of 'Xapril' in patients with chronic heart failure. A paradigm or epitaph for our times? Circulation 90: 1550-1551. [Crossref]

7. Roses AD (2000) Pharmacogenetics and future drug development and delivery. Lancet 355: 1358-1361. [Crossref]
8. Ayanian JZ, Hauptman PJ, Guadagnoli E, Antman EM, Pashos CL, et al. (1994) Knowledge and practices of generalist and specialist physicians regarding drug therapy for acute myocardial infarction. $N$ Engl J Med 331: 1136-1142. [Crossref]

9. Swedberg K, Held P, Kjekshus J, Rasmussen K, Rydén L, et al. (1992) Effects of the early administration of enalapril on mortality in patients with acute myocardial infarction: results of the Cooperative New Scandinavian Enalapril Survival Study II (CONSENSUS II). N Engl J Med 327: 678-684. [Crossref]

10. Pfeffer MA, Braunwald E, Moyé LA, Basta L, Brown EJ Jr, et al. (1992) Effect of captopril on mortality and morbidity in patients with left ventricular dysfunction after myocardial infarction: results of the Survival And Ventricular Enlargement trial (SAVE trial). N Engl J Med 327: 669-677. [Crossref]

11. ACE Inhibitor Myocardial Infarction Collaborative Group (1998) Indications for ACE inhibitors in the early treatment of acute myocardial infarction. Systematic overview of individual data from 100,000 patients in randomized trials. Circulation 97: 2202-2212. [Crossref]

12. Flather MD, Yusuf S, Køber L, Pfeffer M, Hall A, et al. (2000) Long-term ACE inhibito therapy in patients with heart failure or left ventricular dysfunction: a systematic overview of data from individual patients. Lancet 355: 1575-1581. [Crossref]

13. Nakamura M, Funakoshi T, Arakawa N, Yoshida H, Makita S, et al. (1994) Effect of angiotensin-converting enzime inhibitors on endothelium-dependent peripheral vasodilation in patients with chronic heart failure. J Am Coll Cardiol 24: 1321-1327. [Crossref]

14. Lars E, Günter B (2006) Is there a role for amiodarone in the era of the implantable cardioverter-defibrillator? Heart Rhythm 3: 484-487. [Crossref]

15. Hohnloser SH, Dorian P, Roberts R, Gent M, Israel CW, et al. (2006) Effect of amiodarone and sotalol on ventricular defibrillation threshold: the optimal pharmacological therapy in cardioverter defibrillator patients (OPTIC) trial. Circulation 114:104-109.

16. Sequeira OR, Aquino NJ, Gómez NB, García LB, Cáceres C, et al. (2016) AmiodaroneInduced third degree atrioventricular block and extreme QT prolongation generating torsade des points in paroxysmal atrial fibrillation. J Atrial Fib 9: 33-36. [Crossref]

17. Haefeli WE, Linder L, Luscher TF (1997) Quinaprilat induces arterial vasodilation mediated by nitric oxide in humans. Hypertension 30: 912-917.

18. Domanski MJ, Exner DV, Borkowf CB, Geller NL, Rosenberg Y, et al. (1999) Effect of angiotensin converting enzime inhibition on sudden cardiac death in patients following acute myocardial infarction. J Am Coll Cardiol 33:598-604. [Crossref]

19. Pedersen OD, Bagger H, Kober L, Torp-Pedersen C (1999) Trandolapril reduces the incidence of atrial fibrillation after acute myocardial infarction in patients with left ventricular dysfunction. Circulation 100:376-380. [Crossref]

20. Heart Outcome Prevention Evaluation (HOPE) study investigators (2000) Effects of angiotensin-converting enzime inhibitor, ramipril, on cardiovascular events in high risk patients. N Engl J Med 342: 145-153. [Crossref]

Copyright: (C2017 Centurión OA. This is an open-access article distributed under the terms of the Creative Commons Attribution License, which permits unrestricted use, distribution, and reproduction in any medium, provided the original author and source are credited. 